\title{
Spray-Dry Agglomerated Nanoparticles in Ordinary Portland Cement Matrix
}

\author{
Tapio Vehmas, Ulla Kanerva, Erika Holt \\ VTT Technical Research Centre of Finland, Espoo, Finland \\ Email: tapio.vehmas@vtt.fi
}

Received 30 July 2014; revised 10 September 2014; accepted 28 September 2014

Copyright (C) 2014 by authors and Scientific Research Publishing Inc.

This work is licensed under the Creative Commons Attribution International License (CC BY). http://creativecommons.org/licenses/by/4.0/

(c) (i) Open Access

\begin{abstract}
Nano-sized particles have got a focus of great interest for the past decade. These ultrafine particles can have an effect in multiple ways on concrete technology. Although most of the effects of nanoparticles are desired, a huge surface area introduced by nanoparticles also incorporates negative effects, such as loss of workability and safety aspects. Agglomeration of nano-sized particles by spray-drying is one potential method to overcome the negative effects. In this study, ultra-fine material was dispersed and agglomerated successfully. Agglomerate structure was analyzed and performance was evaluated with mortar samples. Agglomerated nano-sized material had micronsized inner porosity, which enabled water penetration into the agglomerates. In water exposure, agglomerates did not dissolve although some of binder glue and dispersing agent leaked out. Water penetration and organic material leaking enabled high reactivity and workability of the agglomerated nanoparticles. In spite of the high reactivity of agglomerated nanoparticles, slightly lower final compression strengths were observed with agglomerated ultrafine particles. The results of this study can be used in concrete technology when further developing admixture technologies and recipe designs. The negative side-effects of the agglomerated nanoparticles can be overcome and accounted for within application areas.
\end{abstract}

\section{Keywords}

\section{Concrete, Nanoparticles, Spray-Drying}

\section{Introduction}

Nano-sized particles have been a focus of great interest for the last decades [1] [2]. Ultrafine particles, usually under a hundred nanometer a diameter, have unique qualities that larger particles of the same materials do not possess. Little by little, nanoparticles have found their way to various applications and the concrete industry is 
no exception [3] [4]. In concrete, these ultrafine particles can have an effect in multiple ways. First they can act as structural components with a reinforcing effect. A good example of this type of behaviour is carbon nanotubes [5] [6]. A second set of mechanisms is the effects with their surface. An example of this type of behaviour is depollution by ultrafine titania [7] [8] and modified hydration kinetics by ultrafine calcium carbonate [9]. High surface area also increases reactivity of nanosilica [10]. Depollution effect of ultrafine titania is based on nitrogen oxide reduction by UV-light and surface catalytic properties of titania [11]. Ultrafine calcium carbonate affects cement hydration through its high surface area, offering additional nucleation sites for calcium-silicatehydrate to precipitate [12]. Also effects of magnetic nanoparticles in concrete have been studied [13].

Although most of the effects of nanoparticles are desired, a huge surface area introduced by nanoparticles also incorporates negative effects. A loss of workability is one property that can hinder the usage of nanoparticles in the concrete industry [14]. A traditional method to overcome this type of problem is to introduce more plasticizing agent. In some cases, this is sufficient to overcome the negative effects, but the detrimental problem of simplifying the nanoparticle usage is not overcome. Also the possible hazardous nature of airborne nanosized particles is still intact [15]. Another way to overcome the problem is to manipulate the composition where the nanoparticles are introduced to concrete. An optimal composition would be a structure, where nanoparticles could maintain their reactivity with a minimal effect on concrete workability, and overcome the hazardous nature of nanosized particles.

In various other industrial applications, powders are processed with a spray-drying method [16]. In the spraydrying method, fine material is agglomerated to larger particles. Depending on the process parameters, shape, size, size distribution and qualities of the agglomerates can be modified. In this study, the goal was to manufacture nanoparticle agglomerates to be utilized in concrete technology with intact reactivity, using the spray-drying method. The spray-drying process was optimized to produce a stable structure through which water could penetrate, enabling reactivity of inner parts of the agglomerate.

Evaluation of the usability of the agglomerates was done in low water/cement-ratio mortars. As there were a number of different possibilities about how these agglomerates could affect the mixes, the mechanisms behind the agglomerates were studied using a viscometer, laser diffraction and UV/VIS-spectroscopy. The structure of the agglomerates was studied with surface acoustic infrared spectroscopy and scanning electron microscopy.

\section{Materials}

Ultrafine precipitated calcium carbonate (PCC, surface area $17-29 \mathrm{~m}^{2} / \mathrm{g}$ ) was chosen for the spray-drying agglomeration. PCC (type Calofort U) was purchased from Specialty Minerals. Two dispersants were tested: Glenium 51 was purchased from BASF (used normally as superplasticizer for concrete) and Dispex N40 from Ciba Specialty Chemicals. Polyvinyl acetate-binder glue (PVA) for the spray-drying process were from Celanese. Starch based binders, Raibond 15 and Raibond 04221 were from Raisio Chemicals. In the mortar samples, the cement used was CEM I 52.5R and aggregates were standard sand according to EN-196.

\section{Methods}

\subsection{Spray-Drying}

PCC agglomerates were manufactured using a spray-drying method. In the spray-drying process, water-based slurry containing fine solid particles and a polymeric binder was introduced into a hot cylinder chamber through a special spray atomisation nozzle. In the hot chamber the moisture was evaporated and spherical agglomerates were formed. Before the actual agglomeration process, there was a pre-stage involving slurry preparation. Careful dispersion of raw materials is a necessity for ensuring the functionality of the agglomeration in the specific application. The slurries were manufactured with a bead mill, which has been proven to be an effective tool for dispersing nano-powders (Hosokawa Alpine, Agitated Lab Ball Mill 90 AHM). Nano-sized material was processed in the bead mill with a dispersing agent until optimal dispersion was achieved. Optimal dispersion was achieved when a gradation measured with laser diffraction did not change. The amount and type of dispersion agent and type of organic binder was varied. Small sample batches for IR-, UV/VIS-, rheology- and dissolution-studies were manufactured with a laboratory scale B-290 spray dryer and larger volumes for mortar samples were manufactured using pilot scale Niro's equipment. Manufactured agglomerates and compositions are listed in Table 1. 
Table 1. Precipitated calcium carbonate agglomerates with spray-drying material compositions.

\begin{tabular}{cccc}
\hline Label & Material & Dispersing agent (w/w) & Binder $(\mathrm{w} / \mathrm{w})$ \\
\hline PCC Agglomerates 1 & PCC & $1 \%$ Glenium 51 & $2 \%$ PVA \\
PCC Agglomerates 2 & PCC & $2 \%$ Glenium 51 & $2 \%$ PVA \\
PCC Agglomerates 3 & PCC & $3 \%$ Glenium 51 & $2 \%$ PVA \\
PCC Agglomerates 4 & PCC & $3 \%$ Dispex N40 & $2 \%$ PVA \\
PCC Agglomerates 5 & PCC & $2 \%$ Glenium 51 & $2 \%$ Raibond 15 \\
PCC Agglomerates 6 & PCC & $2 \%$ Glenium 51 & $2 \%$ Raibond 04221 \\
\hline
\end{tabular}

\subsection{Agglomeration and Agglomerate Structure}

The structure of the produced agglomerates was studied with a scanning electron microscope (JEOLJSM636OVL) and surface acoustic infrared spectroscopy (Biorad FTS 6000, helium purged MTEC300 detector). Scanning electron microscope analyses were made from pristine agglomerates and impregnated thin sections. The particle size distributions of the slurries and the powders were determined by laser diffractometer (Lecotrac LT100) using water as a dispersant in the measurements. The mechanical strength of the powders was tested with an axial die pressing test (MTS 810). Surface acoustic infrared spectroscopy was made with various scanning frequencies, in order to have characteristic signals from various penetration depths. The peak ratio between calcite and polymer (dispersion agent + binder glue) was calculated with various penetration depths. For this purpose, characteristic peaks were indentified as $2511 \mathrm{~cm}^{-1}$ and $1794 \mathrm{~cm}^{-1}$ for calcite and $1738 \mathrm{~cm}^{-1}$ for polymers (dispersion agent + binder glue).

\subsection{Agglomerate Dissolution}

Dissolution of agglomerates was studied in pure water and saturated calcium hydroxide solutions. The agglomerate concentration was $1 \%(\mathrm{w} / \mathrm{w})$ in the measurements. The agglomerates were stirred with a magnetic stirrer for a time as presented in Table 2. The particle distribution was measured by laser diffractometer. Similarly, mixed samples were centrifuged and decanted for UV/VIS-analysis (Hitachi U-2000 Spectrophotometer). The dry material content of the centrifuged liquid phase was determined by drying at $105^{\circ} \mathrm{C}$ for 24 hours. In samples for UV/VIS-analysis, a few drops of diluted salt acid were added, in order to dissolve the particles and get a measure content of dispersion agent and binder glue. The same treatment was also repeated for reference samples. The characteristic peaks, after salt acid treatment, were Glenium 51: $280 \mathrm{~nm}$ and PVA: $255 \mathrm{~nm}$. Absorption coefficients for Glenium 51 were $280 \mathrm{~nm}: 0.103\left(\mathrm{R}^{2}=0.99\right)$ and $255 \mathrm{~nm}: 0.189\left(\mathrm{R}^{2}=0.98\right)$. For PVA, absorption coefficients were $280 \mathrm{~nm}: 0.764\left(\mathrm{R}^{2}=1.00\right)$ and $255 \mathrm{~nm}: 0.395\left(\mathrm{R}^{2}=0.98\right)$. The concentration of dissolved polymers was calculated from UV/VIS-spectra with a standard procedure to differentiate the two component system that have overlapping absorption peaks [17].

\subsection{Rheological Characterization}

The rheological behaviour of the agglomerates was studied with Rheotest RN 4.1 coaxial cylinder viscometer. A certain amount of the initial dry material was replaced by agglomerated particles as presented in Table 3 . The resulting yield stress and plastic viscosity of the slurries were calculated according to the Bingham model.

\subsection{Mortar Samples}

A set of low water/cement-ratio mortars was prepared. Ultra-fine precipitated calcium carbonate was selected for the reference material, due to its ability to accelerate hydration. This quality was also chosen as the reference quality, and the effect of agglomeration of PCC was studied. Mortar samples were produced according to Table 4. Mortars were mixed with a Hobart 5-litre mixer with 5 minute mixing time. Halfway through mixing, the mixing bowl was scraped manually to ensure homogeneity of the prepared samples. Haegermann flow was determined according to DIN1060, immediately after mixing. Hydration was followed using semi-adiabatic calorimeter according to a method described in literature [18]. Three prisms (40 $\mathrm{mm} \times 40 \mathrm{~mm} \times 160 \mathrm{~mm})$ were cast 
Table 2. Laser diffraction results from dissolution studies. Agglomerates were exposed to saturated calcium hydroxide for a given time period. Re-dispersion was not observed in pure water or saturated calcium hydroxide solution.

\begin{tabular}{cccccc}
\hline & & \multicolumn{3}{c}{ Exposure time } \\
PCC Agglomerates 3 & 0 min & 60 min & 120 min & 360 min & 1200 min \\
\cline { 2 - 6 } & $13.7 \%$ & $13.7 \%$ & $14.0 \%$ & $13.5 \%$ & $11.8 \%$ \\
Passing $\mathrm{d} 90(\mu \mathrm{m})$ & $6.1 \%$ & $6.4 \%$ & $6.4 \%$ & $6.1 \%$ & $5.3 \%$ \\
Passing $\mathrm{d} 50(\mu \mathrm{m})$ & $1.4 \%$ & $1.6 \%$ & $1.6 \%$ & $1.4 \%$ & $1.1 \%$ \\
\hline Passing $\mathrm{d} 10(\mu \mathrm{m})$ & & &
\end{tabular}

Table 3. Rheological studies of PCC/agglomerate-slurries. Substitution ratio of PCC with agglomerates varied from $0 \%$ $15 \%$. Yield stress and plastic viscosity was calculated according Bingham model.

\begin{tabular}{|c|c|c|c|c|c|}
\hline \multirow{2}{*}{ Yield stress/Plastic viscosity } & \multicolumn{5}{|c|}{ Substitution ratio } \\
\hline & $0 \%$ & $2.5 \%$ & $5 \%$ & $10 \%$ & $15 \%$ \\
\hline PCC Reference & $377 \mathrm{~Pa} / 0.026 \mathrm{Pas}$ & $-/-$ & $-/-$ & $-/-$ & $-/-$ \\
\hline PCC Agglomerates 2 & $-/-$ & $227 \mathrm{~Pa} / 0.0110$ Pas & $58 \mathrm{~Pa} / 0.0124 \mathrm{Pas}$ & $51 \mathrm{~Pa} / 0.0125$ Pas & $10 \mathrm{~Pa} / 0.0088 \mathrm{Pas}$ \\
\hline PCC Agglomerates 5 & $-/-$ & $237 \mathrm{~Pa} / 0.0126$ Pas & $201 \mathrm{~Pa} / 0.0102 \mathrm{Pas}$ & $151 \mathrm{~Pa} / 0.0108$ Pas & $112 \mathrm{~Pa} / 0.0130 \mathrm{Pas}$ \\
\hline PCC Agglomerates 6 & $-/-$ & $219 \mathrm{~Pa} / 0.0130$ Pas & $190 \mathrm{~Pa} / 0.0111 \mathrm{Pas}$ & $120 \mathrm{~Pa} / 0.0122$ Pas & $80 \mathrm{~Pa} / 0.0125$ Pas \\
\hline
\end{tabular}

Table 4. Recipes and results from studied mortars.

\begin{tabular}{|c|c|c|c|c|c|c|c|c|c|c|}
\hline \multirow{2}{*}{ Sample } & \multicolumn{4}{|c|}{ Mix design ${ }^{*}$} & \multirow{2}{*}{$\begin{array}{l}\text { Haegermann } \\
\text { flow }\end{array}$} & \multirow{2}{*}{ t (dormant) } & \multicolumn{3}{|c|}{ Compression strength (MPa) } & \multirow{2}{*}{$\begin{array}{l}\text { Agglomerate } \\
\text { strength }\end{array}$} \\
\hline & $\mathrm{Ag} / \mathrm{C}$ & w/c & $\mathrm{a} / \mathrm{c}$ & $\mathrm{sp} / \mathrm{c}$ & & & $1 \mathrm{~d}$ & $7 d$ & $28 \mathrm{~d}$ & \\
\hline Ref & 0.00 & 0.35 & 2.30 & 0.01 & $150 \mathrm{~mm}$ & $8.20 \mathrm{~h}$ & 45.1 & 73.6 & 83.0 & - \\
\hline Ref cem & 0.00 & 0.33 & 2.14 & 0.01 & $125 \mathrm{~mm}$ & $8.90 \mathrm{~h}$ & 49.4 & 82.3 & 88.8 & - \\
\hline Ref cem II & 0.00 & 0.30 & 0.30 & 0.01 & $115 \mathrm{~mm}$ & $8.50 \mathrm{~h}$ & 54.3 & 85.2 & 92.0 & - \\
\hline Ref PCC & 0.05 & 0.35 & 2.25 & 0.01 & $160 \mathrm{~mm}$ & $7.00 \mathrm{~h}$ & 53.0 & 79.3 & 88.7 & - \\
\hline PCC Ag. 3 & 0.05 & 0.35 & 2.25 & 0.00 & $150 \mathrm{~mm}$ & $5.80 \mathrm{~h}$ & 42.7 & 60.6 & 88.6 & $0.68 \mathrm{MPa}$ \\
\hline PCC Ag. 4 & 0.05 & 0.35 & 2.25 & 0.00 & $105 \mathrm{~mm}$ & $4.90 \mathrm{~h}$ & 47.1 & 66.7 & 76.4 & $1.16 \mathrm{MPa}$ \\
\hline PCC Ag. 1 & 0.05 & 0.35 & 2.25 & 0.00 & $120 \mathrm{~mm}$ & $5.50 \mathrm{~h}$ & 47.9 & 66.2 & 75.4 & $0.64 \mathrm{MPa}$ \\
\hline
\end{tabular}

${ }^{*} \mathrm{Ag} / \mathrm{c}=$ Agglomerates/cement; w/c = water/cement; a/c = aggregates/cement;sp/c = superplasicizer/cement.

for each testing age, $1 \mathrm{~d}, 7 \mathrm{~d}$ and $28 \mathrm{~d}$. The prisms were stored at RH 100\% for the first day. During ages $1 \mathrm{~d}-28$ $\mathrm{d}$, the samples were stored underwater until the testing age. Compression strength experiments were done according to EN196-1.

\section{Results}

\subsection{Agglomerate Structure}

Scanning electron microscope (SEM) analysis revealed that the spray-drying method produced highly rounded particles with smooth surfaces (Figure 1). The size distribution of the agglomerates varied between $1 \mu \mathrm{m}-60$ $\mu \mathrm{m}$, having the largest peak at $20 \mu \mathrm{m}$ (Figure 2). Undispersed and dispersed samples had peaks around $1 \mu \mathrm{m}$ and $0.1 \mu \mathrm{m}$, respectively. From impregnated thin sections, it was found that agglomerates had a micron sized inner porosity (Figure 1). No significant difference between the inner core and surface could be observed. The uppermost surface layer of the agglomerates was analysed using surface acoustic infrared spectroscopy. Infrared 

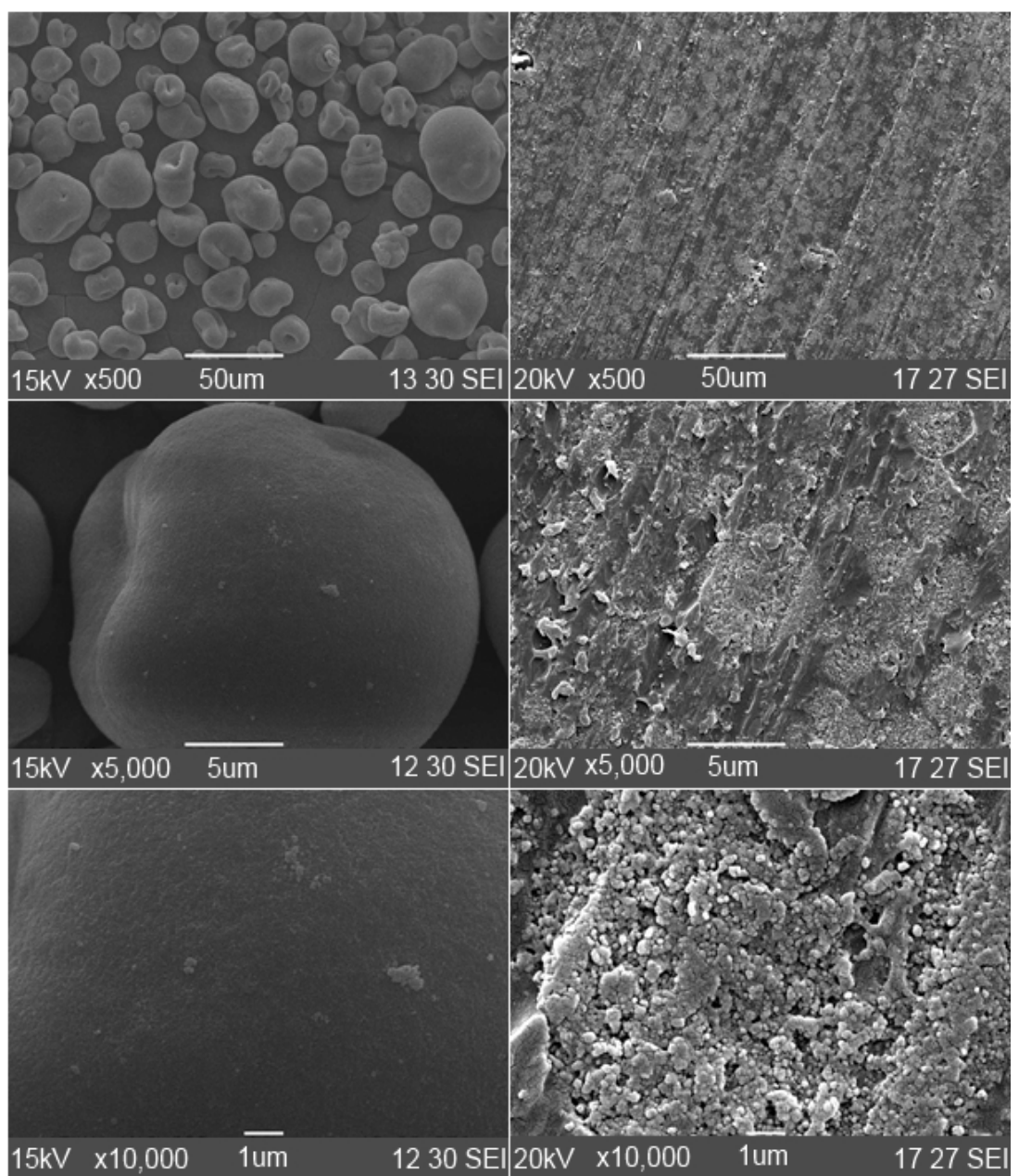

Figure 1. Scanning electron microscopy images of pristine PCC agglomerates 3 and impregnated + polished section of PCC agglomerates 3 .

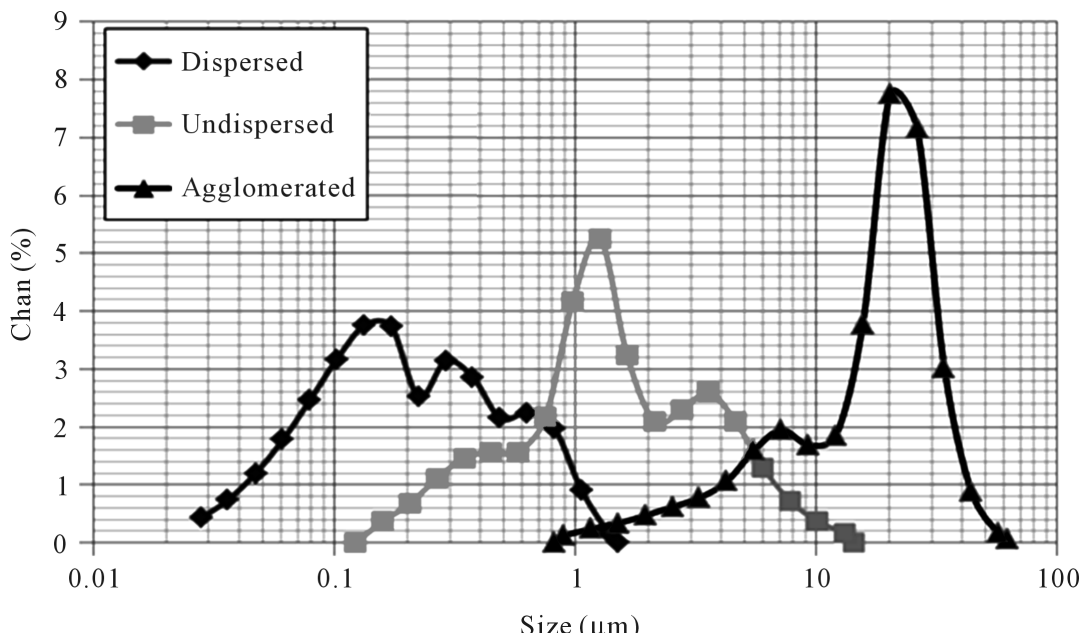

Figure 2. Particle size of undispersed ultrafine calcium carbonate, dispersed ultrafine calcium carbonate and ultrafine calcium carbonate agglomerated with spray-drying method. Agglomerated particles had diameter $\sim 20 \mu \mathrm{m}$, whereas undispersed had mean diameter $\sim 1 \mu \mathrm{m}$ and dispersed $\sim 0.1 \mu \mathrm{m}$. 
spectroscopy signals from the PCC and the organic binder were compared with various penetration depths (Table 5). It was found that the organic material/PCC-signal ratio was relatively constant at various penetration depths. The changes in signal ratios were comparable to PCC/PCC-ratio changes which indicated that changes were within the limit of divergence. IR-analysis concluded that the polymers and initial material were evenly distributed throughout the whole surface layer to bulk layer.

\subsection{Agglomerate Dissolution and Rheology}

Table 2 presents results from the dissolution studies in saturated calcium hydroxide and pure water solutions. Degradation of agglomerates did not happen during measurements as can be seen from laser diffraction studies in Table 2. Exposure to water or saturated calcium hydroxide solution did not significantly dissolve the agglomerates. A small amount of dissolution happened. The content of dissolved material was determined with UV/VIS-spectroscopy. The centrifuged phase of dissolution samples was dim and dissolution of particles with salt acid was necessary in order to perform UV/VIS-measurement. It was observed that notable dissolution of the dispersing agent and binder glue from agglomerates happened (Figure 3). The amount of dissolved Glenium was $0.026 \mathrm{~g} / \mathrm{g}$ and PVA $0.024 \mathrm{~g} / \mathrm{g}$ for PCC agglomerates 2 . The amount of dissolved Glenium was $0.055 \mathrm{~g} / \mathrm{g}$ and PVA $0.026 \mathrm{~g} / \mathrm{g}$ for PCC agglomerates 3 . These amounts were compared to the total dry material concentration

Table 5. Results of infrared spectroscopy study. Scanning frequencies and signal ratios for polymers and PCC. (PCC = Precipitated Calcium Carbonate, Polymers = Glenium 51, PVA). Various scanning frequencies correspond to various penetration depths, $40 \mathrm{kHz}$ absorbed on top layers and $2.5 \mathrm{kHz}$ penetrated deepest into sample.

\begin{tabular}{cccccc}
\hline & \multicolumn{3}{c}{ Scanning frequency } \\
\cline { 2 - 5 } PCC Agglomerates 4 & $40 \mathrm{kHz}$ & $20 \mathrm{kHz}$ & $10 \mathrm{kHz}$ & $5 \mathrm{kHz}$ & $2.5 \mathrm{kHz}$ \\
\hline $\begin{array}{c}\text { PCC/PCC-ratio } \\
\left(2511 \mathrm{~cm}^{-1} / 1794 \mathrm{~cm}^{-1}\right)\end{array}$ & 1.003 & 1.002 & 0.978 & 0.934 & 0.944 \\
$\begin{array}{c}\text { Polymers/PCC-ratio } \\
\left(1738 \mathrm{~cm}^{-1} / 2511 \mathrm{~cm}^{-1}\right)\end{array}$ & 0.083 & 0.064 & 0.087 & 0.081 & 0.080 \\
\hline
\end{tabular}

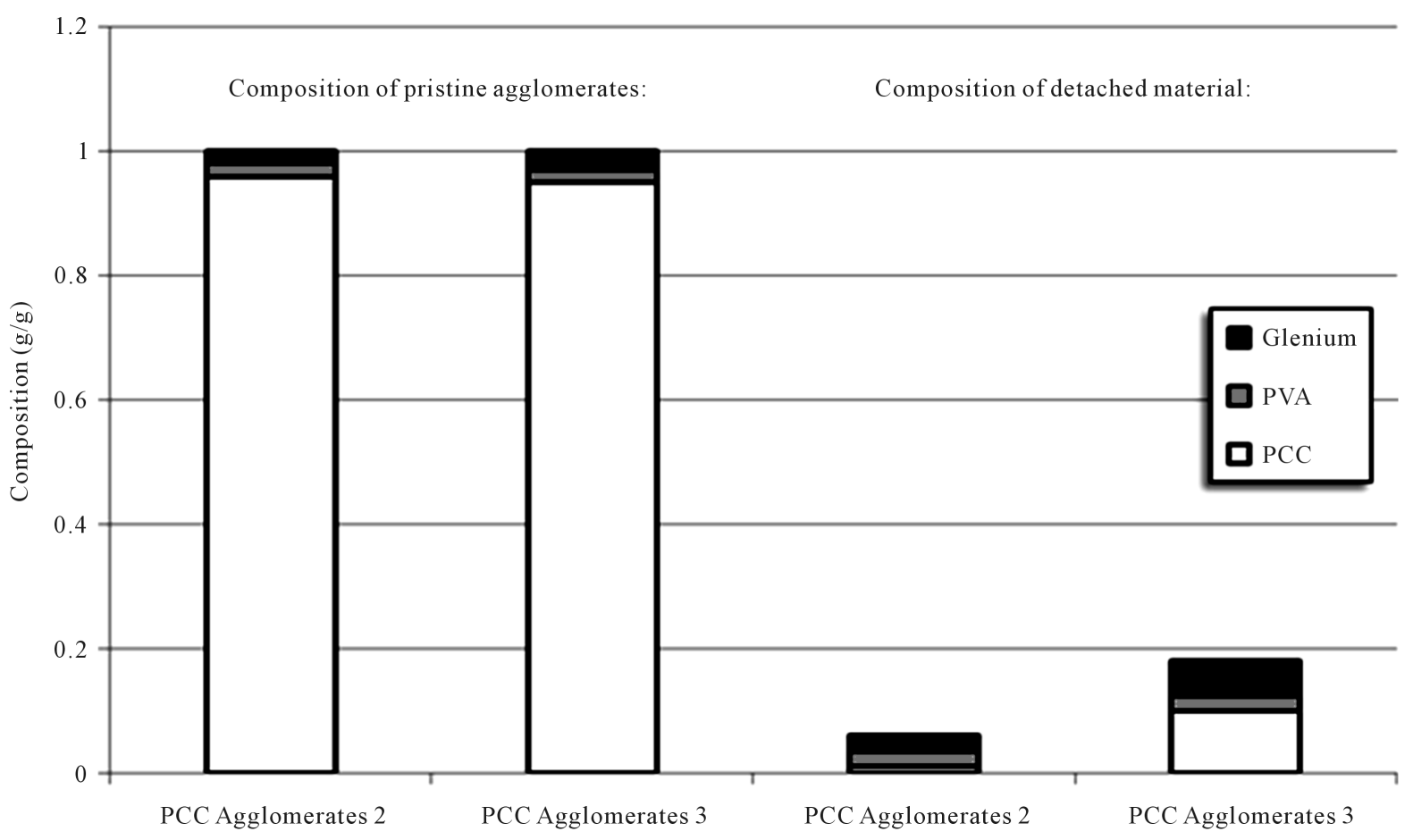

Figure 3. Composition of pristine PCC agglomerates and detached material in water solution. Agglomerate content of the studies slurry was $1 \%$. Majority of the leached materials was binder glue or dispersing agent. 
and the difference was assumed to present detached PCC-content. It was concluded that the organic material dissolved significantly more than pure decomposition of agglomerates would produce.

\subsection{Performance Characterization}

A small replacement of the initial nano-material with agglomerates, produced a huge reduction in the initial yield stresses of the PCC slurries (Table 3). This phenomenon was also observed in mortar-samples. PVA/Glenium-combination had largest plasticizing effect. Further evaluation revealed that the plasticizing effect can be mainly explained with superplasticizer leakage from the agglomerated particles, but the effects of the highly rounded particles could not be ruled out.

Results from mortar experiments are listed in Table 4. Addition of PCC shortened the dormant period and agglomerated PCC particles had the same effect. The Haegermann flow of studied mortars varied between 100 $\mathrm{mm}-160 \mathrm{~mm}$. Compression strengths of mortars containing agglomerates were slightly lower than reference mortars. Agglomerate strength did not a have correlation to mortar prisms' compression strengths.

\section{Discussion}

The spray-drying method proved to be an effective technique to agglomerate nanoparticles to a desired composition. The agglomerated particles were a composite of nanoparticles, dispersing agent and binder glue. According to SEM observations, these agglomerated nanoparticles were highly rounded with micron-sized inner porosity. The composition between the surface and inner core did not differ. Laser measurements revealed that no significant dissolution of agglomerates happened in aqueous- or saturated calcium hydroxide solutions. In rheology measurements, a huge plasticizing effect was observed when small portion of initial nanoparticles were replaced with agglomerated particles. The leakage of binder glue and dispersing agent was found to be the main reason for the plasticizing effect. The leakage of polymers from agglomerated particles enabled water to penetrate into the agglomerated particles. The penetrated water made it possible for the inner surfaces of agglomerates to react, which can explain the high reactivity of agglomerated nanoparticles.

In order to estimate benefits gained by agglomeration, a set of mortars was studied. The reference quality, hydration acceleration, was judged against the flowing ability of the mortars. The reference samples had a dormant period approximately 8 - 9 hours. Addition of ultra-fine precipitated calcium carbonate lowered the dormant period to 7 hours. Addition of agglomerated particles produced mortars with dormant period of 5 - 6 hours. With agglomerated particles, it was also seen that the leaked superplasticizer lengthened the dormant period, but the effect was smaller compared to mortars with PCC and superplasticizer.

The negative effects of this agglomeration method were observed in compression strengths. The compression strengths were lower with agglomerate-samples compared to the reference samples. The precipitated calcium carbonate/superplasticizer-combination enhanced compression strengths in $1 \mathrm{~d}$ results, slowly lowering over time to the reference level. Agglomerate-samples had lower compression strengths from day one and the effect was emphasized with time. Agglomerated particles probably caused microstructural defects to the samples, therefore lowering the compression strengths which were largely dependent on the quality of the microstructure [19]-[21]. Agglomerate strength did not have any correlation to the mortar sample compression strengths. It is also likely that other qualities which are largely depended on microstructure could also be affected, e.g. durability.

\section{Conclusion}

The spray-drying method was effective at agglomerating ultra-fine particles used in concrete technology. Agglomeration improved workability of mortars with nanosized particles, while still maintaining the high reactivity of nanoparticles. The high reactivity originated from the beneficial water penetration to the agglomerates, which was mainly caused by leaking of organic material from the agglomerates. These qualities made it possible to produce highly-reactive and -flowable mortar. Agglomeration method provided easy method to overcome dusting effect of pristine ultra-fine particles. Another method to overcome dusting is to use nanoparticles as slurries. However, slurries will introduce additional water, increasing transportation volumes and complicating mix design. With agglomeration method, both negative aspects of pristine- and slurry-ultrafine particles were avoided. Large agglomerated particles can ease handling of nanoparticles, if the safety issues prove to be relevant. Agglomeration was observed to have a negative effect to mortars microstructure, causing lowering of compression 
strengths. The results of this study can be used in concrete technology when further developing admixture technologies and recipe designs. The negative side-effects of the agglomerated nanoparticles can be overcome and accounted for within application areas.

\section{References}

[1] Maynard, A.D. (2006) Nanotechnology: Assessing the Risks. Nano Today, 1, 22-33. http://dx.doi.org/10.1016/S1748-0132(06)70045-7

[2] Maynard, A.D. (2007) Nanotechnology: The Next Big Thing, or Much Ado about Nothing? Annals of Occupational Hygiene, 51, 1-12. http://dx.doi.org/10.1093/annhyg/mel071

[3] Sanchez, F. and Sobolev, K. (2010) Nanotechnology in Concrete-A Review. Construction and Building Materials, 24, 2060-2071. http://dx.doi.org/10.1016/j.conbuildmat.2010.03.014

[4] Pacheco-Torgal, F. and Jalali, S. (2011) Nanotechnology: Advantages and Drawbacks in the Field of Construction and Building Materials. Construction and Building Materials, 25, 582-590. http://dx.doi.org/10.1016/j.conbuildmat.2010.07.009

[5] Li, G.Y., Wang, P.M. and Zhao, X. (2005) Mechanical Behavior and Microstructure of Cement Composites Incorporating Surface-Treated Multi-Walled Carbon Nanotubes. Carbon, 43, 1239-1245. http://dx.doi.org/10.1016/j.carbon.2004.12.017

[6] Li, G.Y., Wang, P.M. and Zhao, X. (2007) Pressure-Sensitive Properties and Microstructure of Carbon Nanotube Reinforced Cement Composites. Cement and Concrete Composites, 29, 377-382. http://dx.doi.org/10.1016/j.cemconcomp.2006.12.011

[7] Ibusuki, T. and Takeuchi, K. (1994) Removal of Low Concentration Nitrogen Oxides through Photoassisted Heterogeneous Catalysis. Journal of Molecular Catalysis, 88, 93-102. http://dx.doi.org/10.1016/0304-5102(93)E0247-E

[8] Ballari, M.M., Hunger, M., Hasken, G. and Brouwers, H.J.H. (2010) $\mathrm{NO}_{\mathrm{x}}$ Photocatalytic Degradation Employing Concrete Pavement Containing Titanium Dioxide. Applied Catalysis B: Environmental, 95, 245-254. http://dx.doi.org/10.1016/j.apcatb.2010.01.002

[9] Sato, T. and Diallo, F. (2010) Seeding Effect of Nano-CaCO $\mathrm{C}_{3}$ on the Hydration of Tricalcium Silicate. Journal of the Transportation Research Record, 2141, 61-67.

[10] Mondal, P., Shah, S., Marks, L. and Gaitero, J. (2010) Comparative Study of the Effects of Microsilica and Nanosilica in Concrete. Transportation Research Record, 2141, 6-9.

[11] Cassar, L. (2004) Photocatalysis of Cementitious Materials: Clean Buildings and Clean Air. MRS Bulletin, 5, 328-331. http://dx.doi.org/10.1557/mrs2004.99

[12] Stark, J., Möser, B. and Bellmann, F. (2007) Nucleation and Growth of C-S-H Phases on Mineral Admixtures. Advances in Construction Materials, 531-538.

[13] Blyszko, J., Kiernozycki, W., Guskos, N., Zolnierkiewicz, G., Typek, J., Narkiewicz, U. and Podsiadly, M. (2008) Study of Mechanical Properties of Concrete with Low Concentration of Magnetic Nanoparticles. Journal of Non Crystalline Solids, 354, 4515-4518. http://dx.doi.org/10.1016/j.jnoncrysol.2008.06.101

[14] Nazari, A. and Riahi, S. (2010) Assessment of the Effects of $\mathrm{Fe}_{2} \mathrm{O}_{3}$ Nanoparticles on Water Permeability, Workability, and Setting Time of Concrete. Journal of Composite Materials, 45, 923-930. http://dx.doi.org/10.1177/0021998310377945

[15] Donaldson, K., Stone, V., Clouter, A., Renwick, L. and MacNee, W. (2001) Ultrafine Particles. Occupational and Environmental Medicine, 58, 211-216. http://dx.doi.org/10.1136/oem.58.3.211

[16] Shaw, F. and Andrews, M. (1997) Spray Drying, Carbide, Nitride and Boride Materials Synthesis and Processing. Chapman \& Hall, London.

[17] Harris, D.C. (2003) Quantitative Chemical Analysis. 6th Edition, W.H. Freeman and Company, New York.

[18] TCE1 (1997) Adiabatic and Semi-Adiabatic Calorimetry to Determine the Temperature Increase in Concrete Due to Hydration Heat of the Cement. Materials and Structures, 30, 451-464. http://dx.doi.org/10.1007/BF02524773

[19] Därr, G.M. and Ludwig, U. (1973) Determination of Permeable Porosity. Materials and Structures, 6, 185.

[20] Rostasy, F.S., Weib, R. and Wiedemann, G. (1980) Changes of Pore Structure of Cement Mortar due Temperature. Cement and Concrete Research, 10, 157-164. http://dx.doi.org/10.1016/0008-8846(80)90072-1

[21] Kumar, R. and Bhattacharjee, B. (2003) Porosity, Pore Size Distribution and In-Situ Strength of Concrete. Cement and concrete research, 33, 155-164. http://dx.doi.org/10.1016/S0008-8846(02)00942-0. 
Scientific Research Publishing (SCIRP) is one of the largest Open Access journal publishers. It is currently publishing more than 200 open access, online, peer-reviewed journals covering a wide range of academic disciplines. SCIRP serves the worldwide academic communities and contributes to the progress and application of science with its publication.

Other selected journals from SCIRP are listed as below. Submit your manuscript to us via either submit@scirp.org or Online Submission Portal.
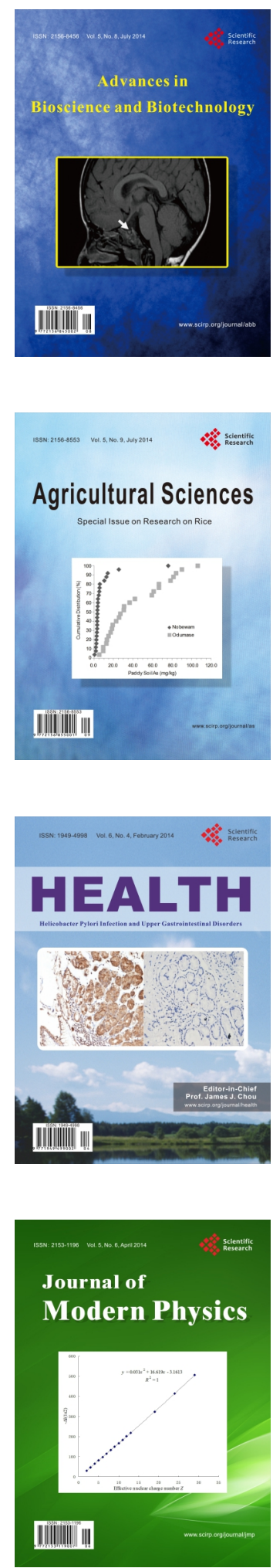
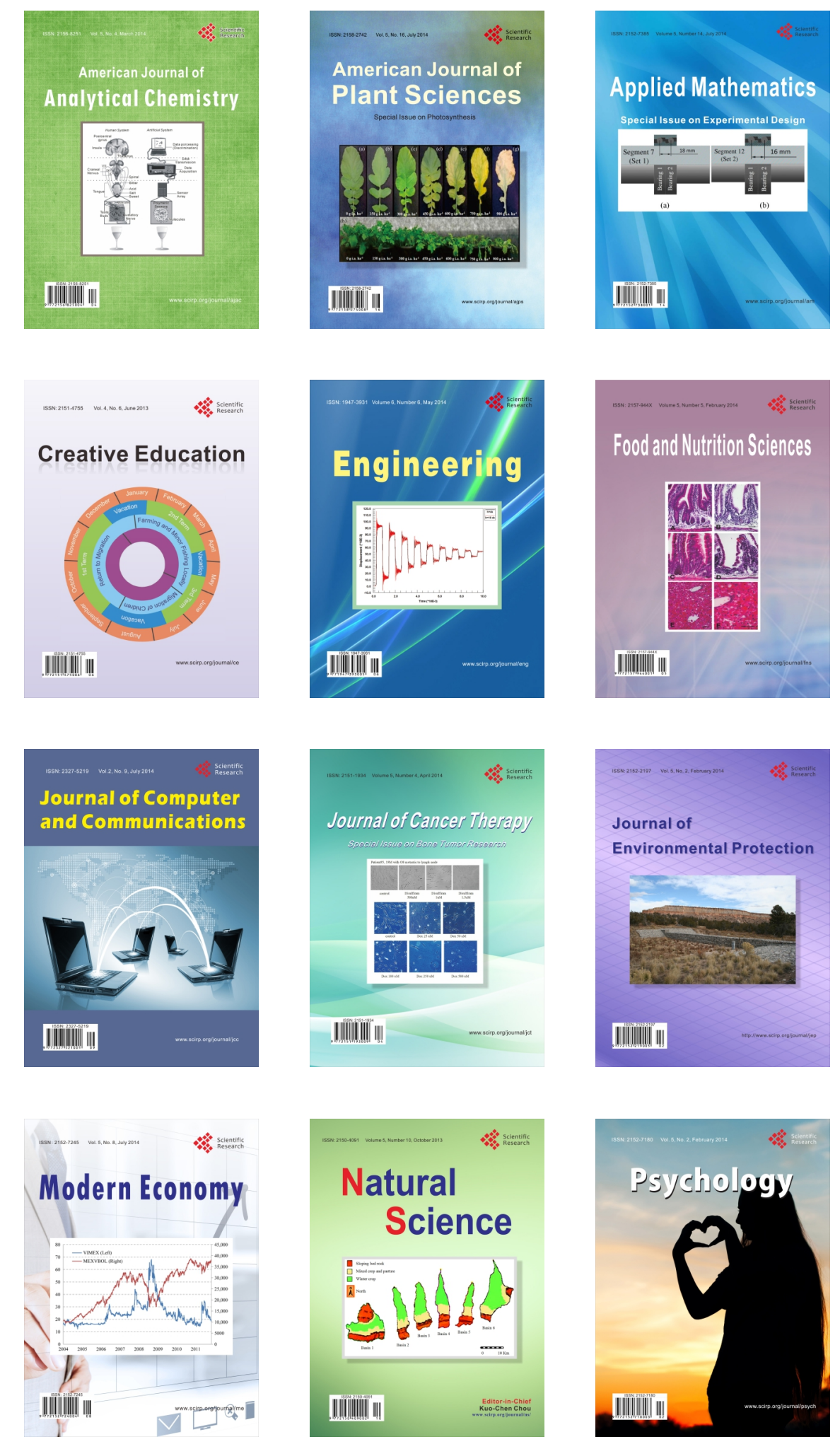